\title{
Post-glucose-load urinary C-peptide and glucose concentration obtained during OGTT do not affect oral minimal model-based plasma indices
}

\author{
Sjaam Jainandunsing ${ }^{1} \cdot$ J. L. Darcos Wattimena ${ }^{1} \cdot$ Trinet Rietveld $^{1}$. \\ Joram N. I. van Miert ${ }^{1} \cdot$ Eric J. G. Sijbrands ${ }^{1} \cdot$ Felix W. M. de Rooij ${ }^{1}$
}

Received: 21 August 2015/ Accepted: 28 September 2015/Published online: 2 November 2015

(c) The Author(s) 2015. This article is published with open access at Springerlink.com

\begin{abstract}
The purpose of this study was to investigate how renal loss of both C-peptide and glucose during oral glucose tolerance test (OGTT) relate to and affect plasmaderived oral minimal model (OMM) indices. All individuals were recruited during family screening between August 2007 and January 2011 and underwent a 3.5-h OGTT, collecting nine plasma samples and urine during OGTT. We obtained the following three subgroups: normoglycemic, at risk, and T2D. We recruited South Asian and Caucasian families, and we report separate analyses if differences occurred. Plasma glucose, insulin, and C-peptide concentrations were analyzed as AUCs during OGTT, OMM estimate of renal C-peptide secretion, and OMM beta-cell and insulin sensitivity indices were calculated to obtain disposition indices. Post-glucose load glucose and C-peptide in urine were measured and related to plasmabased indices. Urinary glucose corresponded well with plasma glucose AUC (Cau $r=0.64, P<0.01$; SA $r=$ $0.69, P<0.01$ ), $S_{\text {I }}$ (Cau $r=-0.51, P<0.01 ;$ SA $r=$ $-0.41, P<0.01), \Phi_{\text {dynamic }}($ Cau $r=-0.41, P<0.01$; SA $r=-0.57, \quad P<0.01), \quad$ and $\Phi_{\text {oral }}$ (Cau $r=-0.61$, $P<0.01$; SA $r=-0.73, P<0.01$ ). Urinary C-peptide corresponded well to plasma C-peptide AUC (Cau $r=0.45, P<0.01 ;$ SA $r=0.33, P<0.05)$ and OMM estimate of renal C-peptide secretion $(r=0.42, P<0.01)$. In general, glucose excretion plasma threshold for the presence of glucose in urine was $\sim 10-10.5 \mathrm{mmol} \mathrm{L}^{-1}$ in non-T2D individuals, but not measurable in T2D
\end{abstract}

Felix W. M. de Rooij

f.derooij@erasmusmc.nl

1 Department of Internal Medicine, Erasmus MC - University Medical Center Rotterdam, Room Na-512, PO-box 2040, 3000 CA Rotterdam, The Netherlands individuals. Renal glucose secretion during OGTT did not influence OMM indices in general nor in T2D patients (renal clearance range $0-2.1 \%$, with median $0.2 \%$ of plasma glucose AUC). C-indices of urinary glucose to detect various stages of glucose intolerance were excellent (Cau 0.83-0.98; SA 0.75-0.89). The limited role of renal glucose secretion validates the neglecting of urinary glucose secretion in kinetic models of glucose homeostasis using plasma glucose concentrations. Both C-peptide and glucose in urine collected during OGTT might be used as non-invasive measures for endogenous insulin secretion and glucose tolerance state.

Keywords Type 2 diabetes - OGTT - Oral minimal model $\cdot$ C-peptide $\cdot$ Glucose $\cdot$ South Asian
Abbreviations
AUC Area under curve
DI Disposition Index
eGFR Estimated glomerular filtration rate
IS Insulin sensitivity
MDRD Modification of diet in renal disease
OMM Oral minimal model
ROC Receiver-operated characteristics

\section{Introduction}

Mathematical approaches based on compartmental pharmacokinetic/pharmacodynamic (PK/PD) principles are used to describe the biphasic glucose-insulin system in oral function tests [1, 2], with the oral minimal model (OMM) as one of the most widely accepted approaches [3]. 
However, the contribution of renal clearance of endogenous glucose, insulin, and C-peptide during oral glucose tolerance test (OGTT) in various stages of glucose tolerance remains largely unclear. As renal extraction of insulin is negligible [4], we focused on the relationship between plasma and urine concentrations of both C-peptide and glucose, collected during OGTT in the post-glucose load phase. This was performed in families to obtain groups with different risk for T2D, and we recruited families of South Asian and Caucasian origin to enable generalization of our findings. Especially, South Asians with T2D may be at high risk for chronic kidney disease [5]. We questioned to which degree C-peptide and glucose excretion in urine influence OGTT-based plasma indices. Moreover, we compared the OMM-derived estimates of renal C-peptide excretion with actual urinary $\mathrm{C}$-peptide concentration. In addition, renal loss of glucose is not taken into consideration in OMM, and the extent to which renal clearance might require correction of plasma-derived OMM calculations is unknown.

\section{Methods}

\section{Subjects and anthropometric data}

Patients were recruited from South Asian and Caucasian families with high risk of T2D after family screening from the Outpatient Clinic of the Erasmus Medical University Centre as described previously [6]. The first-degree relatives of patients with T2D attending our Clinic (index cases), who did not have T2D were recruited from 36 South Asian families and 24 Caucasian families, with 2 generations taken into account. Data were obtained from 57 (M29 F28) South Asians and 64 (M24 F40) Caucasians who all underwent an OGTT. Index cases were on metformin use only and had at least one sibling with T2D. Informed written consent to the study was obtained from all participants. The study protocol was approved by the Erasmus University Medical Center Medical Ethics Review Board. All procedures followed were in accordance with the ethical standards of the responsible committee on human experimentation (institutional and national) and with the Helsinki Declaration of 1975, as revised in 2008.

\section{OGTT}

Venous blood was drawn via an intravenous canula, at time-points 60 and $15 \mathrm{~min}$ before $75 \mathrm{~g}$ glucose load and $15,30,45,60,90,120,150,180$, and $210 \mathrm{~min}$ after glucose load to measure glucose, insulin, and C-peptide concentrations. The WHO criteria for the OGTT were used to define normal glucose tolerance (NGT), impaired fasting glucose and/or impaired glucose tolerance (IFG/IGT), or
Type 2 diabetes (T2D) status among subjects. After emptying their bladder prior to glucose load, urine was collected until $210 \mathrm{~min}$ after glucose load. As there were no significant differences between baseline values of plasma glucose, insulin, or C-peptide obtained at $-60 \mathrm{~min}$ or $-15 \mathrm{~min}$, and as $-60 \mathrm{~min}$ was sampled before our study subjects had emptied their bladder prior to glucose load, we chose $-60 \mathrm{~min}$ as the representative baseline value. In 7 of 18 Caucasians with T2D, urine was not collected, because it was not included in our protocol at that time. As this group did not significantly differ from the remaining group, we used data of $n=18$ for all plasma indices, but data of $n=11$ for all analyses with urinary glucose and C-peptide measurements in Caucasians.

\section{Immunoassay}

Plasma and urine glucose was measured by a hexokinasebased method (Gluco-quant; Roche Diagnostics, Mannheim, Germany). Plasma and urine C-peptide, and plasma insulin were measured separately by a competitive chemiluminescent immunoassay, supplied by Euro/DPC. The assay was performed on a DPC Immulite 2000 analyzer (Euro/DPC) according to the manufacturer's recommended protocol. Serum creatinine was measured with an enzymatic procedure based on creatinine conversion with the Creatinine Plus assay on a Roche/Hitachi analyzer. Urine creatinine was measured based on the Jaffe alkaline picrate method.

\section{Calculations for OMM}

The OMM was used to describe the plasma glucose, insulin, and C-peptide concentrations after oral glucose stimulus [7]. With C-peptide minimal model, we assessed parameters for beta-cell function: basal responsivity of beta-cells due to basal glucose potentiation $\Phi_{\text {basal }}\left(\mathrm{min}^{-1}\right)$, static responsivity of beta-cells due to glucose potentiation $\Phi_{\text {static }}\left(10^{-9} \min ^{-1}\right)$, dynamic responsivity of beta-cells due to glucose potentiation $\Phi_{\text {dynamic }}\left(10^{-9}\right)$, total responsivity of beta-cells due to glucose potentiation $\Phi_{\text {oral }}$ $\left(10^{-9} \mathrm{~min}^{-1}\right)$, and delay in response to glucose potentiation $T$ (min). With glucose minimal model, we assessed parameters for insulin sensitivity, insulin sensitivity $S_{\mathrm{I}}$ $\left(10^{-5} \mathrm{dL} \mathrm{kg}^{-1} \mathrm{~min}^{-1}\right.$ per $\left.\mathrm{pM}\right)$. Parameters from both models were multiplied with each other for calculation of disposition indices (DI), which are beta-cell function measures corrected for insulin sensitivity: $\mathrm{DI}_{\text {basal }}=$ $\Phi_{\text {basal }} * S_{\mathrm{I}}, \mathrm{DI}_{\text {static }}=\Phi_{\text {static }} * S_{\mathrm{I}}, \mathrm{DI}_{\text {dynamic }}=\Phi_{\text {dynamic }} * S_{\mathrm{I}}$, and $\mathrm{DI}_{\text {oral }}=\Phi_{\text {oral }} * S_{\mathrm{I}}$. Parameters of OMM were estimated with SAAM2 software [8]. Incremental plasma AUC of C-peptide and glucose within a given time period was calculated according to trapezoidal rule, with subtraction of 
basal concentration. For urinary glucose, we estimated plasma glucose threshold (when exceeded glucose in urine is present) separately among both our T2D and non-T2D (NGT + IFG/IGT) groups; we calculated plasma glucose AUCs from 8.5 to $11.5 \mathrm{mmol} \mathrm{L}^{-1}$ with an interval of $0.5 \mathrm{mmol} \mathrm{L}^{-1}$ to detect the most suitable plasma glucose threshold. Stepwise exclusion was performed of T2D and non-T2D individuals, based on whether their plasma glucose AUC was above a given threshold or not. Also, to determine the relative renal loss of glucose from total plasma glucose AUC, renal clearance of glucose was calculated with absolute amount of urinary glucose/total plasma glucose AUC. For comparison with urinary C-peptide, we used AUC from flux $k_{01}$ (Fig. 1) from OMM, representing irreversibly metabolized C-peptide from central compartment. Estimated glomerular filtration rate (eGFR) was estimated with the modification of diet in renal disease (MDRD) formula $[9,10]$.
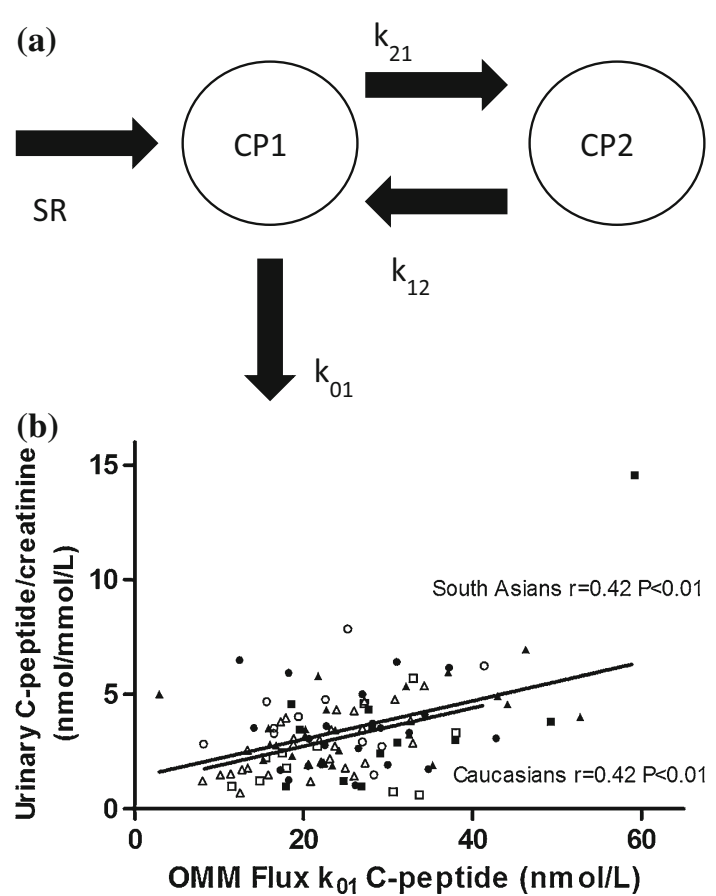

Fig. 1 a Two-compartment model of C-peptide kinetics that is integrated in oral minimal model (OMM). SR is prehepatic insulin secretion rate, based on C-peptide curve. CP1 represents the amount of C-peptide in central compartment and CP2 the amount of C-peptide in peripheral compartment. $k_{21}$ and $k_{12}$ are C-peptide transfer rates between $\mathrm{CP} 1$ and $\mathrm{CP} 2 ; k_{01}$ describes metabolization of C-peptide from CP1. In this study, plasma AUC of CP1* $k_{01}$, or OMM flux $k_{01}$, is related to actual measured C-peptide concentration in urine during OGTT. Adapted from van Cauter et al. [1]. b Correlation between C-peptide in urine and OMM flux $k_{01}$. NGT (triangle), IFG/ IGT (square), and T2D (circle) subgroups for South Asian (closed) and Caucasian (open) families

\section{Statistical analyses}

\section{Data analysis}

Data are expressed as mean $\pm \mathrm{SEM}$, or indicated otherwise. Comparisons within the subgroups of the ethnicities were done with ANOVA, with the other two subgroups of same ethnicity and with the corresponding other ethnic subgroup. Differences were considered statistically significant when the two-sided $P$ value was $<0.0125$. Urinary glucose and C-peptide were correlated with plasma indices, with Spearman correlation within each ethnicity, with significance at $P$ value $<0.05$. For urinary glucose and $C$-peptide concentrations, AUC of receiver-operated characteristics (ROC) curves (concordance indices or c-indices), adjusted for family ties by binary logistic regression analysis [11], were calculated to detect IFG/IGT and/or T2D status. All statistical tests were conducted with the use of SPSS, version 15.0, for Windows (SPSS Inc., Chicago, IL, USA).

\section{Results}

\section{Baseline characteristics}

Baseline characteristics are shown in Table 1 and incremental plasma AUC of primary data glucose, insulin, and C-peptide during OGTT in Fig. 2. South Asian T2D individuals were younger $(P=0.004)$, shorter $(P<0.001)$, and weighed less $(P=0.005)$ than Caucasian T2D individuals. W/H increased from NGT to T2D in Caucasians $(P=0.003)$, but not in South Asians. In both ethnicities, incremental plasma glucose AUCs from NGT or IFG/IGT were significantly lower than T2D $(P<0.001)$. In both ethnicities, no significant differences were found in incremental plasma insulin AUC between NGT, IFG/IGT, and T2D; however, a difference was found between South Asian NGT and Caucasian NGT $(P<0.01)$. In both ethnicities, no significant differences were found in incremental plasma C-peptide AUC between NGT, IFG/IGT, and T2D. In both ethnicities, no significant differences were found in $\Phi_{\text {basal }}$ between NGT, IFG/IGT, and T2D, whereas, $\Phi_{\text {dynamic }}, \Phi_{\text {static }}$, and $\Phi_{\text {total }}$ decreased with increasing glucose intolerance. No significant differences were found in delay $T$. With OMM, we observed a decrease in insulin sensitivity in both ethnicities with increasing glucose intolerance $(P<0.001)$; however, differences were lower among the South Asian subgroups. All disposition indices decreased with increasing glucose intolerance. Overall, South Asian NGT and IFG/IGT demonstrated lower DI indices when compared to Caucasian NGT, whereas those of South Asian T2D were higher than their 


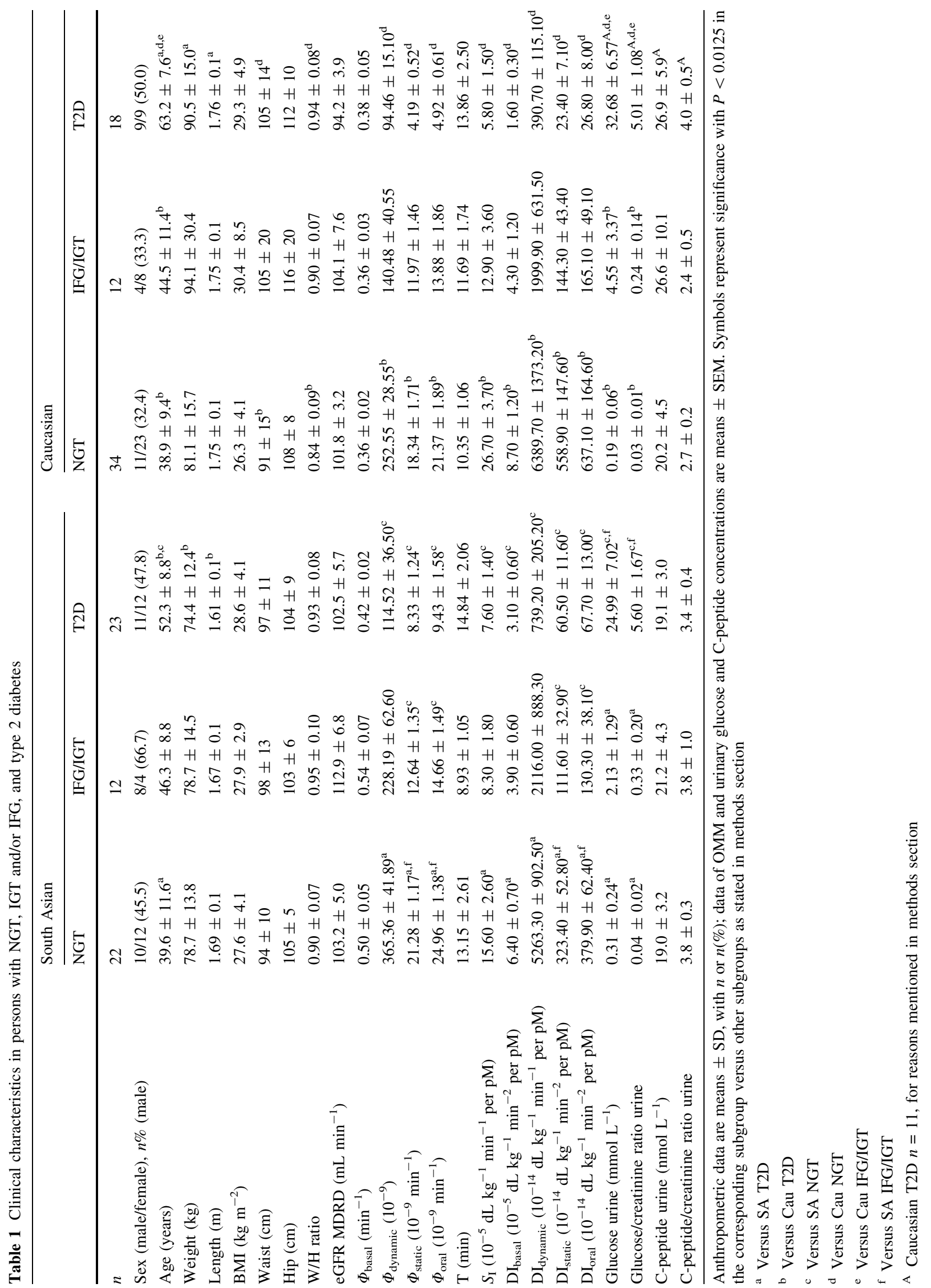



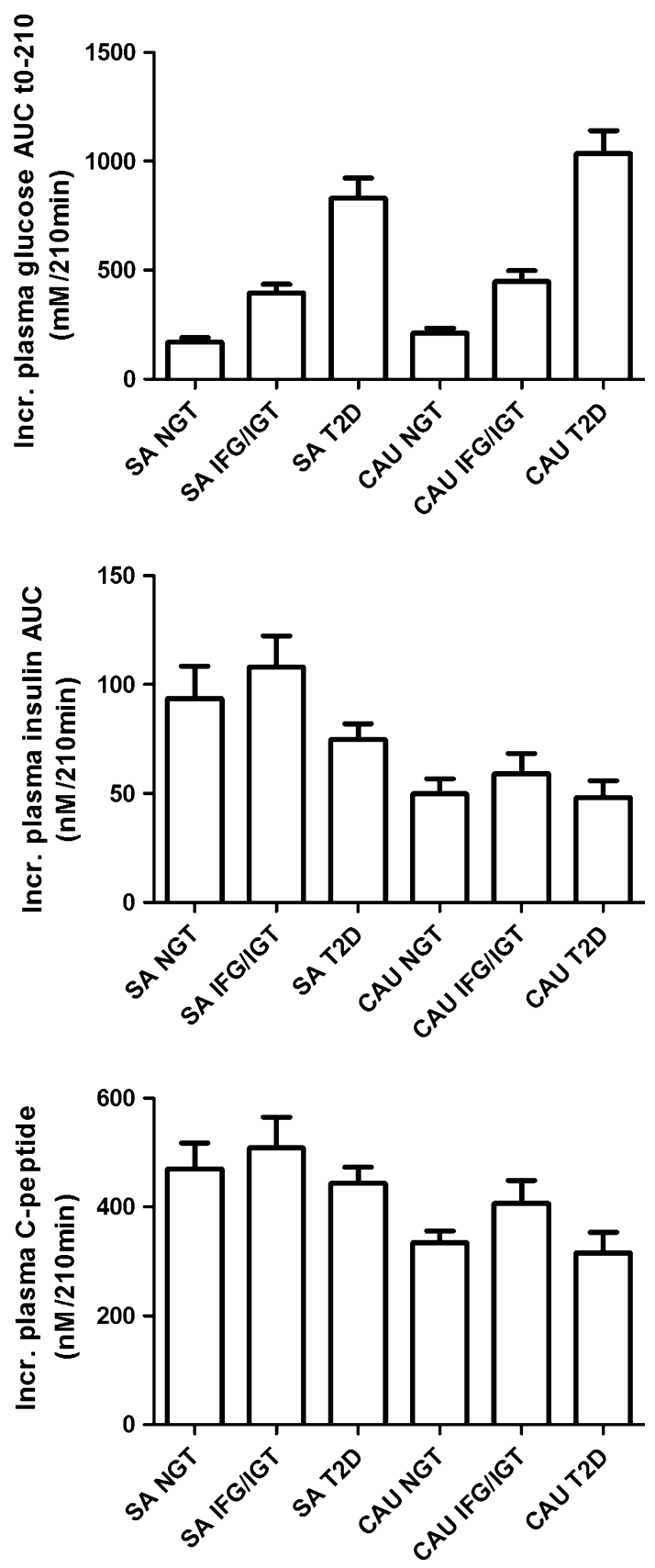

Fig. 2 Incremental plasma AUC of glucose, insulin and C-peptide during 210 min OGTT (mean \pm SEM) among WHO OGTT subgroups with normal glucose tolerance (NGT), impaired fasting glucose and/or impaired glucose tolerance (IFG/IGT) and Type 2 diabetes (T2D) from South Asian (SA) or Caucasian (Cau) origin. Incr. plasma glucose AUC; SA NGT versus T2D SA $P<0.001$, SA IFG/IGT versus T2D $P<0.001$, Cau NGT versus Cau T2D $P<0.001$, CauIFG/IGT versus Cau T2D $P<0.001$. Incr. plasma insulin AUC; SA NGT versus Cau NGT $P<0.01$. Please note different scale in $\mathrm{Y}$-axis for insulin and $\mathrm{C}$-peptide.

Caucasian counterparts. In both ethnicities, glucose in urine increased with increasing glucose intolerance; both creatinine-unadjusted and adjusted urinary glucose in T2D subgroup were significantly higher when compared to
NGT or IFG/IGT subgroups $(P<0.001)$. In Caucasians, creatinine adjusted C-peptide was higher in T2D when compared to NGT and IFG/IGT combined ( $T$ test $P=0.005)$; no differences were found among South Asians.

\section{Effect of renal glucose loss on plasma-derived OMM indices}

The absolute amount of glucose concentration collected in urine voids of T2D patients did not influence glucose minimal model measurements, as a result of the small variation of renal clearance (range 0-2.1\%, with median $0.2 \%$ of total plasma glucose AUC).

\section{Relation urine markers with plasma indices of C-peptide and glucose, OMM, and eGFR}

Relationships between urinary glucose and C-peptide with plasma indices in both ethnicities can be found in Table 2 . In both ethnicities, urinary glucose was positively associated with plasma glucose AUC and negatively associated with $S_{\mathrm{I}}$ and DI values. In both ethnicities, urinary C-peptide was positively associated with plasma C-peptide AUC. Plasma AUC of OMM flux $k_{01}$ reflecting C-peptide from central compartment that is irreversibly metabolized, correlated with creatinine-adjusted urinary C-peptide (Fig. 2; $r=0.42 ; P<0.01)$. Creatinine-unadjusted and adjusted urinary glucose as well as C-peptide had no significant correlation with eGFR.

\section{Estimation of glucose threshold among non-T2D and T2D subgroups}

Our stepwise exclusion approach to estimate glucose threshold during OGTT can be found in Table 3. It led to glucose threshold of $\sim 10 \mathrm{mmol} \mathrm{L}^{-1}$ among Caucasian NGT and IFG/IGT individuals. In South Asians, glucose threshold for NGT and IFG/IGT individuals did not differ much, being $\sim 10.5 \mathrm{mmol} \mathrm{L}^{-1}$. Glucose threshold during OGTT varied considerably among T2D patients from both ethnicities and was therefore not assessable.

\section{ROC values of urine markers for detection of glucose tolerance state}

We examined the areas under ROC curves of glucose and $\mathrm{C}$-peptide in urine unadjusted as well as adjusted for creatinine (adjusted are the values between brackets), respectively. We have found clear differences between the two ethnicities and therefore performed separate analyses. Urinary glucose concentration demonstrated high capability to discriminate between T2D and the combination of the 
Table 2 Spearman correlation between urine markers and plasma indices

\begin{tabular}{llllllll}
\hline Urine markers & Plasma indices & & & & \\
\cline { 2 - 7 } & Incr C-peptide AUC & Incr. glucose AUC & $S_{\text {I }}$ & $\Phi_{\text {dynamic }}$ & $\Phi_{\text {static }}$ & $D_{\text {dynamic }}$ & DI $_{\text {static }}$ \\
\hline South Asians & & & & & & & \\
Glucose urine & -0.023 & $0.757^{* *}$ & $-0.459^{* *}$ & $-0.578^{* *}$ & $-0.774^{* *}$ & $-0.687^{* *}$ & $-0.730^{* *}$ \\
Glucose/creatinine ratio urine & -0.059 & $0.690^{* *}$ & $-0.414^{* *}$ & $-0.565^{* *}$ & $-0.727^{* *}$ & $-0.653^{* *}$ & $-0.674^{* *}$ \\
C-peptide urine & $0.331^{*}$ & 0.170 & -0.151 & 0.153 & 0.036 & 0.010 & -0.060 \\
C-peptide/creatinine ratio urine & $0.301^{*}$ & 0.069 & -0.148 & 0.100 & 0.068 & -0.057 & -0.002 \\
Caucasians & & & & & & & \\
Glucose urine & 0.175 & $0.669^{* *}$ & $-0.639^{* *}$ & -0.208 & $-0.571^{* *}$ & $-0.663^{* *}$ & $-0.763^{* *}$ \\
Glucose/creatinine ratio urine & 0.036 & $0.644^{* *}$ & $-0.513^{* *}$ & $-0.412^{* *}$ & $-0.610^{* *}$ & $-0.687^{* *}$ & $-0.656^{* *}$ \\
C-peptide urine & $0.485^{* *}$ & $0.346^{*}$ & $-0.458^{* *}$ & 0.178 & -0.039 & -0.269 & $-0.398^{* *}$ \\
C-peptide/creatinine ratio urine & $0.453^{* *}$ & 0.254 & -0.202 & -0.055 & -0.053 & -0.198 & -0.168 \\
\hline
\end{tabular}

$* P<0.05, * * P<0.01$

other two subgroups (NGT and IFG/IGT), 0.976 (0.996) in Caucasians and 0.893 (0.898) in South Asians, respectively. We also calculated c-indices of urinary glucose for NGT versus the combination of IFG/IGT and T2D, 0.904 (0.908) in Caucasians and 0.894 (0.877) in South Asians, and c-indices for NGT versus the IFG/IGT subgroup, 0.826 (0.827) in Caucasians and 0.748 (0.736) in South Asians, respectively (Fig. 3).

The c-indices of urinary C-peptide concentration for the detection of glucose tolerance status were for discrimination between T2D and the combination of two other subgroups, 0.658 (0.742) in Caucasians and 0.503 (0.565) in South Asians, respectively. The c-indices for NGT versus the combination of IFG/IGT and T2D were $0.692(0.733)$ in Caucasians and 0.556 (0.584) in South Asians. The c-indices for NGT versus IFG/IGT were 0.792 (0.792) in Caucasians and 0.595 (0.599) in South Asians, respectively (Fig. 3).

\section{Discussion}

We found that urinary C-peptide collected during OGTT correlated with plasma C-peptide indices and OMMderived estimates of renal $\mathrm{C}$-peptide excretion. Urinary glucose collected during OGTT also correlated well with plasma indices, especially with plasma glucose AUC. Urinary glucose was mainly present in urine of patients with T2D; however, the loss of glucose in the urine was too small to influence general OMM calculations. Among the patients with T2D, the urinary glucose concentration showed large variation but discriminated well between normal and abnormal glucose tolerance.

Both glucose minimal model and C-peptide minimal model assess plasma glucose concentrations during OGTT with the first model also applying an area under the curve constraint; the amount of circulating glucose is expected to be a fixed parameter based on the amount of glucose load used as stimulus. The knowledge about the effects of dynamic glucose loss on OMM-based parameters due to renal handling after stimulus is limited [7]. We hypothesized that the variance of the urinary glucose excretion could be a serious confounder, but we found that renal loss of glucose does not influence OMM-based parameters of insulin sensitivity and beta-cell function. This finding is highly relevant for glucose homeostasis based kinetic models in general.

Overnight, 24-h fasting, and after a mixed meal, urine collection studies demonstrated the value of urinary C-peptide as non-invasive measure for endogenous insulin secretion in people with and without diabetes [12-17]. As stricter metabolic control affects urinary C-peptide, it might be of use to follow-up the insulin secretory function [18-20]. In line, we found that during OGTT, urinary $\mathrm{C}$-peptide correlated well with plasma values reflecting the endogenous pancreatic secretion. For urinary C-peptide, we did not observe a relationship between eGFR MDRD. This is in agreement with previous studies, where the presence of micro albuminuria or renal impairment with reduced filtration rate did not alter the relationship between urinary and plasma C-peptide [21, 22].

Glucose is cleared by the kidney and predominantly reabsorbed by the sodium-glucose co-transporter 2 (SGLT2) in the proximal tubules. The urinary glucose excretion threshold is believed to be around $10 \mathrm{mmol} \mathrm{L}^{-1}$ in individuals without T2D [23, 24], which is in accordance with our estimations, with the exception of our individuals with T2D. Our patients with T2D did not use SGLT2 inhibitors. With clamp steady-state studies, it was demonstrated that a glucose threshold is not applicable to individuals with T2D due to a large variation in their glucose excretion; and glucosuria is present even when treated 
Table 3 Two groups, one with and one without glucose in urine

\begin{tabular}{lllll}
\hline Caucasians $^{\mathrm{A}}$ & & & South Asians \\
\cline { 2 - 3 } & Glucose AUC & & (stepwise) & Glucose AUC
\end{tabular}

Threshold $8.5 \mathrm{mmol} \mathrm{L}^{-1}$

Urine glucose-

Non-T2D
T2D

3

Urine glucose+

Non-T2D 19

T2D

19

Threshold 9 mmol L ${ }^{-1}$

Urine glucose-

Non-T2D
T2D

Urine glucose+

$\begin{array}{ll}\text { Non-T2D } & 16 \\ \text { T2D } & 1\end{array}$

Threshold $9.5 \mathrm{mmol} \mathrm{L}^{-1}$

Urine glucose-

$\begin{array}{ll}\text { Non-T2D } & 2 \\ \text { T2D } & 0\end{array}$

Urine glucose+

$\begin{array}{ll}\text { Non-T2D } & 11 \\ \text { T2D } & 11\end{array}$

Threshold $10 \mathrm{mmol} \mathrm{L}^{-1}$

Urine glucose-

$\begin{array}{ll}\text { Non-T2D } & 0 \\ \text { T2D } & 0\end{array}$

Urine glucose+

$\begin{array}{lr}\text { Non-T2D } & 9 \\ \text { T2D } & 11\end{array}$

Threshold $10.5 \mathrm{mmol} \mathrm{L}^{-1}$

Urine glucose-

Non-T2D
T2D

Urine glucose+

$\begin{array}{lr}\text { Non-T2D } & 8 \\ \text { T2D } & 11\end{array}$

Threshold $11.0 \mathrm{mmol} \mathrm{L}^{-1}$

Urine glucose-

$\begin{array}{ll}\text { Non-T2D } & 0 \\ \text { T2D } & 0\end{array}$

Urine glucose+

$\begin{array}{lr}\text { Non-T2D } & 8 \\ \text { T2D } & 11\end{array}$

Threshold $11.5 \mathrm{mmol} \mathrm{L}^{-1}$

Urine glucose-

\begin{tabular}{|c|c|c|c|c|}
\hline Non-T2D & 0 & 0 & 0 & 0 \\
\hline $\mathrm{T} 2 \mathrm{D}$ & 0 & 0 & 0 & 0 \\
\hline \multicolumn{5}{|c|}{ Urine glucose+ } \\
\hline Non-T2D & 7 & $38.6 \pm 13.4$ & 4 & $21.2 \pm 13.0$ \\
\hline
\end{tabular}

$\begin{array}{lrl}28.8 \pm 14.7 & 2 & 71.25 \pm 57.0 \\ 0 & 1 & 33.8 \\ & & \\ 116.6 \pm 29.3 & 14 & 116.2 \pm 28.9 \\ 1012.9 \pm 143.4 & 20 & 684.5 \pm 107.0\end{array}$

$17.25 \pm 6.0$

$41.3 \pm 37.5$

12.0

$99.7 \pm 26.0$

$614.0 \pm 102.2$

$2.25 \pm 1.50$

45.8

0

$75.8 \pm 23.0$

$545.1 \pm 97.3$

16.5

0

$67.5 \pm 22.4$

$480.3 \pm 91.8$

$759.3 \pm 128.5 \quad 20$

0

0

$77.6 \pm 20.6$

$46.9 \pm 18.6$

$683.1 \pm 123.2$

$420.5 \pm 85.8$
Non-T2D
0

0

$53.3 \pm 16.5$

$608.8 \pm 117.8$
$25.9 \pm 13.9$

$383.8 \pm 81.4$

0

0 
Table 3 continued

\begin{tabular}{llllll}
\hline & Caucasians $^{\mathrm{A}}$ & & & \multicolumn{2}{l}{ South Asians } \\
\cline { 2 - 3 } & $N$ (stepwise) & Glucose AUC & & $N$ (stepwise) & Glucose AUC \\
\hline T2D & 11 & $538.9 \pm 111.8$ & 17 & $367.0 \pm 78.7$
\end{tabular}

With increasing glucose threshold, stepwise exclusion was performed separately among non-T2D (NGT + IFG/IGT) and T2D subgroups, based on their absence of having above threshold glucose AUC (mean \pm SEM)

${ }^{\text {A }}$ Caucasian $\mathrm{T} 2 \mathrm{D} n=11$, for reasons mentioned in methods section

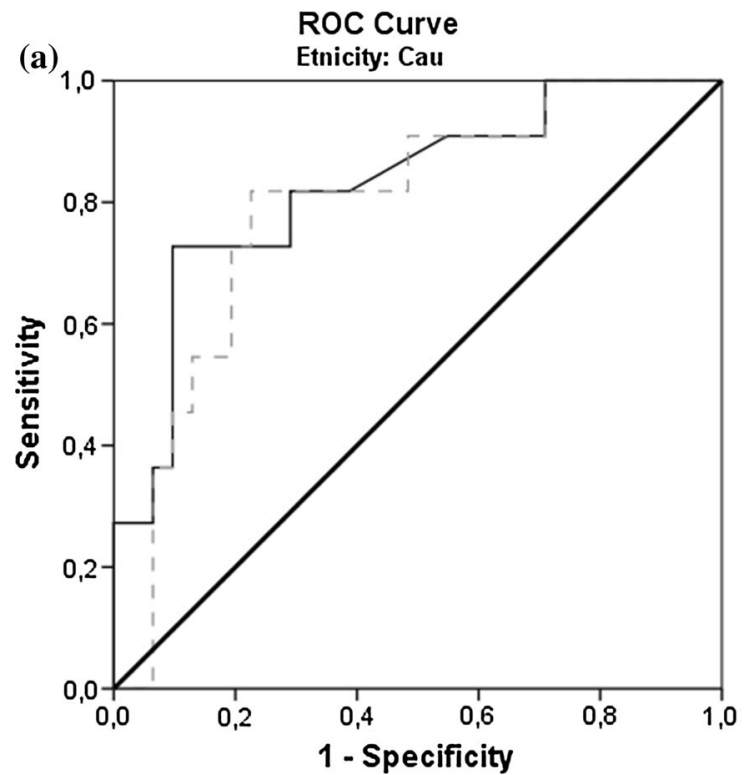

Fig. 3 a, b Receiver-operated characteristics (ROC) curve for discriminatory ability between individuals with normal glucose tolerance (NGT) versus impaired fasting glucose/impaired glucose tolerance (IFG/IGT) with urinary glucose (closed line) or C-peptide

patients with T2D return to euglycemic conditions $[25,26]$. Hence, using the OGTT the post-glucose-load urinary glucose concentration may be useful as non-invasive marker to detect abnormal glucose tolerance, but it is not suited to monitor treatment.

The strength of the present study lies in the fact that we used OMM and assessed urine parameters in two different ethnicities and in all stages of glucose tolerance. Among the weaknesses of our study are the limited sample size, the limited possibilities to translate our findings of the extended OGTT into clinical applications and using estimate eGFR MDRD instead of measuring GFR directly as a measure for renal function. Although our groups were relatively small, differences between subgroups and ethnicities became apparent with this relatively simple and low-cost test procedure. In contrast to the customary 24-h urine collections obtained at home, we collected urine in

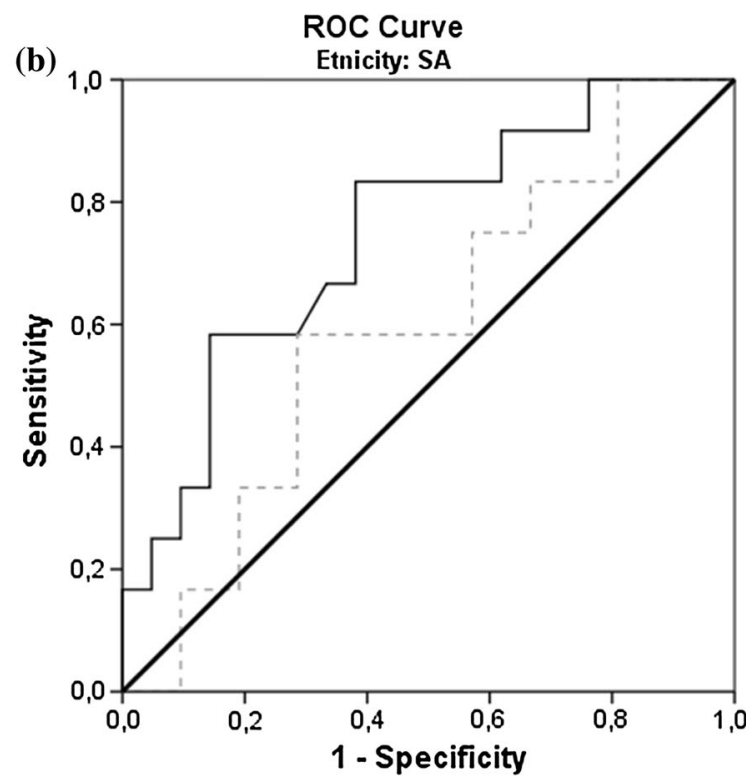

(dashed line) concentration obtained from urine collected during OGTT (both unadjusted for urine creatinine), in Caucasians (a) and South Asians (b)

the hospital setting, during an extended version of OGTT. Validity of reduced amount of sampling and sampling time after stimulus has been demonstrated previously in healthy individuals, resulting in a more practical application of OMM [27]. We were also able to reduce amount of sampling, as we found no significant differences between plasma indices obtained from our above-described final 210 min-post-glucose load nine samples OGTT versus an earlier performed pilot with 210 min-post-glucose load 13 samples OGTT, which also included sampling at $t=5$, $t=10, t=20$ and $t=25 \mathrm{~min}$ (data not shown). The participants in our study had no severe kidney failure and no history of renal disease.

In conclusion, urinary C-peptide corresponded well to OMM-derived estimates of renal C-peptide clearance and the renal glucose secretion during OGTT did not influence OMM indices. 
Acknowledgments We sincerely thank The Epsilon Group and notably Enrique Campos-Nanez for contributing to Oral Minimal Model development.

Author contribution S. J. performed the experiments, analyzed and researched data, reviewed and edited the manuscript, and contributed to discussion. J. L. D. W., T. R., and J. N. I. van M. helped with handling of samples and glucose, insulin, and C-peptide measurements and contributed to discussion. F. W. M. de R. and E. J. G. S. are the guarantors of this work and, as such, had full access to all the data in the study and take responsibility for the integrity of the data and the accuracy of the data analysis. All individuals gave final approval before publication.

\section{Compliance with ethical standards}

Conflict of interest There are no potential conflicts of interest relevant to this article.

Open Access This article is distributed under the terms of the Creative Commons Attribution 4.0 International License (http://crea tivecommons.org/licenses/by/4.0/), which permits unrestricted use, distribution, and reproduction in any medium, provided you give appropriate credit to the original author(s) and the source, provide a link to the Creative Commons license, and indicate if changes were made. The Creative Commons Public Domain Dedication waiver (http://creativecommons.org/publicdomain/zero/1.0/) applies to the data made available in this article, unless otherwise stated.

\section{References}

1. E. Van Cauter, F. Mestrez, J. Sturis, K.S. Polonsky, Estimation of insulin secretion rates from C-peptide levels. Comparison of individual and standard kinetic parameters for C-peptide clearance. Diabetes 41(3), 368-377 (1992)

2. R.P. Eaton, R.C. Allen, D.S. Schade, K.M. Erickson, J. Standefer, Prehepatic insulin production in man: kinetic analysis using peripheral connecting peptide behavior. J. Clin. Endocrinol. Metab. 51(3), 520-528 (1980)

3. M.G. Pedersen, A. Corradin, G.M. Toffolo, C. Cobelli, A subcellular model of glucose-stimulated pancreatic insulin secretion. Philos. Transact. A Math. Phys. Eng. Sci. 366(1880), 3525-3543 (2008)

4. M.J. Chamberlain, L. Stimmler, The renal handling of insulin. J. Clin. Invest. 46(6), 911-919 (1967)

5. G. Dreyer, S. Hull, R. Mathur, A. Chesser, M.M. Yaqoob, Progression of chronic kidney disease in a multi-ethnic community cohort of patients with diabetes mellitus. Diabet. Med. 30(8), 956-963 (2013). doi:10.1111/dme.12197

6. S. Jainandunsing, B. Ozcan, T. Rietveld, J.N. van Miert, A.J. Isaacs, J.G. Langendonk, F.W. de Rooij, E.J. Sijbrands, Failing beta-cell adaptation in South Asian families with a high risk of type 2 diabetes. Acta Diabetol. (2014). doi:10.1007/s00592-014-0588-9

7. E. Breda, M.K. Cavaghan, G. Toffolo, K.S. Polonsky, C. Cobelli, Oral glucose tolerance test minimal model indexes of beta-cell function and insulin sensitivity. Diabetes 50(1), 150-158 (2001)

8. P.H. Barrett, B.M. Bell, C. Cobelli, H. Golde, A. Schumitzky, P. Vicini, D.M. Foster, SAAM II: Simulation, Analysis, and Modeling Software for tracer and pharmacokinetic studies. Metabolism 47(4), 484-492 (1998)

9. A.S. Levey, J.P. Bosch, J.B. Lewis, T. Greene, N. Rogers, D. Roth, A more accurate method to estimate glomerular filtration rate from serum creatinine: a new prediction equation. Modification of diet in Renal Disease Study Group. Ann. Intern. Med. 130(6), 461-470 (1999)
10. E.D. Poggio, X. Wang, T. Greene, F. Van Lente, P.M. Hall, Performance of the modification of diet in renal disease and Cockcroft-Gault equations in the estimation of GFR in health and in chronic kidney disease. J. Am. Soc. Nephrol. 16(2), 459-466 (2005)

11. J.S. Mills, K.W. Mahaffey, Y. Lokhnygina, J.C. Nicolau, W. Ruzyllo, P.X. Adams, T.G. Todaro, P.W. Armstrong, C.B. Granger, Prediction of enzymatic infarct size in ST-segment elevation myocardial infarction. Coron. Artery Dis. 23(2), 118-125 (2012). doi:10.1097/MCA.0b013e32834e4f8f

12. H. Tillil, E.T. Shapiro, B.D. Given, P. Rue, A.H. Rubenstein, J.A. Galloway, K.S. Polonsky, Reevaluation of urine C-peptide as measure of insulin secretion. Diabetes 37(9), 1195-1201 (1988)

13. N. Sasaki, S. Miyamoto, H. Niimi, H. Nakajima, C-peptide/creatinine ratio in early morning urine as an indicator of residual B-cell function in insulin-dependent diabetes. Acta Paediatr. Jpn. 33(3), 375-380 (1991)

14. R.G. Brodows, Use of urinary C-peptide to estimate insulin secretion during starvation. J. Clin. Endocrinol. Metab. 61(4), 654-657 (1985)

15. R.E. Besser, J. Ludvigsson, A.G. Jones, T.J. McDonald, B.M. Shields, B.A. Knight, A.T. Hattersley, Urine C-peptide creatinine ratio is a noninvasive alternative to the mixed-meal tolerance test in children and adults with type 1 diabetes. Diabetes Care 34(3), 607-609 (2011)

16. R.E. Besser, M.H. Shepherd, T.J. McDonald, B.M. Shields, B.A. Knight, S. Ellard, A.T. Hattersley, Urinary C-peptide creatinine ratio is a practical outpatient tool for identifying hepatocyte nuclear factor 1-\{alpha\}/hepatocyte nuclear factor 4-\{alpha\} maturity-onset diabetes of the young from long-duration type 1 diabetes. Diabetes Care 34(2), 286-291 (2011)

17. A.G. Jones, R.E. Besser, T.J. McDonald, B.M. Shields, S.V. Hope, P. Bowman, R.A. Oram, B.A. Knight, A.T. Hattersley, Urine C-peptide creatinine ratio is an alternative to stimulated serum C-peptide measurement in late-onset, insulin-treated diabetes. Diabet. Med. 28(9), 1034-1038 (2011)

18. Y. Aoki, Variation of endogenous insulin secretion in association with treatment status: assessment by serum C-peptide and modified urinary C-peptide. Diabetes Res. Clin. Pract. 14(3), 165-173 (1991)

19. S.D. Hsieh, Y. Iwamoto, A. Matsuda, T. Kuzuya, Reduction in urine C-peptide clearance rate after metabolic control in NIDDM patients. Endocrinol. Jpn. 35(4), 601-606 (1988)

20. H.J. Gjessing, L.E. Matzen, A. Froland, O.K. Faber, Correlations between fasting plasma C-peptide, glucagon-stimulated plasma C-peptide, and urinary C-peptide in insulin-treated diabetics. Diabetes Care 10(4), 487-490 (1987)

21. P. Bowman, T.J. McDonald, B.M. Shields, B.A. Knight, A.T. Hattersley, Validation of a single-sample urinary C-peptide creatinine ratio as a reproducible alternative to serum C-peptide in patients with Type 2 diabetes. Diabet. Med. 29(1), 90-93 (2012)

22. T. Wasada, H. Kuroki, H. Arii, A. Maruyama, K. Katsumori, K. Aoki, S. Saito, Y. Omori, Hyperglycemia facilitates urinary excretion of C-peptide by increasing glomerular filtration rate in non-insulin-dependent diabetes mellitus. Metabolism 44(9), 1194-1198 (1995)

23. J.E. Gerich, Role of the kidney in normal glucose homeostasis and in the hyperglycaemia of diabetes mellitus: therapeutic implications. Diabet. Med. 27(2), 136-142 (2010)

24. R.A. DeFronzo, J.A. Davidson, S. Del Prato, The role of the kidneys in glucose homeostasis: a new path towards normalizing glycaemia. Diabetes Obes. Metab. 14(1), 5-14 (2012)

25. S. Wolf, K. Rave, L. Heinemann, K. Roggen, Renal glucose excretion and tubular reabsorption rate related to blood glucose in subjects with type 2 diabetes with a critical reappraisal of the "renal glucose threshold" model. Horm. Metab. Res. 41(8), 600-604 (2009) 
26. K. Rave, L. Nosek, J. Posner, T. Heise, K. Roggen, E.J. van Hoogdalem, Renal glucose excretion as a function of blood glucose concentration in subjects with type 2 diabetes-results of a hyperglycaemic glucose clamp study. Nephrol. Dial. Transplant. 21(8), 2166-2171 (2006)
27. C. Dalla Man, M. Campioni, K.S. Polonsky, R. Basu, R.A. Rizza, G. Toffolo, C. Cobelli, Two-hour seven-sample oral glucose tolerance test and meal protocol: minimal model assessment of beta-cell responsivity and insulin sensitivity in nondiabetic individuals. Diabetes 54(11), 3265-3273 (2005) 